\title{
Genetic diversity of Plasmodium falciparum and genetic profile after artemisinin-based combination therapy (ACTs) deployment in Cameroon for the management of uncomplicated malaria in Children
}

Metoh Theresia Njuabe ( $\nabla$ njuabe@yahoo.fr)

The University of Bamemda https://orcid.org/0000-0003-3010-4380

Jun-Hu Chen

NIPD-CDC Shanghai

Philip Fon Gah

The University of Bamenda

Zhou Xia

NIPD-CDC Shanghai

Somo.Roger Moyou

The University of Yaounde I

Xiao-Nong Zhou

NIPD-CDC Shanghai

Research article

Keywords: Plasmodium falciparum, msp-1, msp-2, glurp, heterozygosity, Multiplicity of infection,

Cameroon

Posted Date: May 17th, 2019

DOI: https://doi.org/10.21203/rs.2.9648/v1

License: (c) (i) This work is licensed under a Creative Commons Attribution 4.0 International License.

Read Full License 


\section{Abstract}

Background Plasmodium falciparum is the number one cause of malaria morbidity and mortality. Several methods of intervention have been deployed in Cameroon with an attempt to reduce malaria transmission. But evaluation methods mostly based on microscopy and immunology have proven to be cumbersome and expensive. This study aimed at analyzing the genetic diversity of P.falciparum and the impact of ACTs deployment on MOI Method 350 clinical isolates were collected between 2012 and 2013 and, three P. falciparum loci namely, msp-1(block2), msp-2 (block3), and glurp, (region II) characterized by nested PCR and DNA sequencing. Results From this study, a total of 16 different pfmsp1 were identified, including K1, MAD20 and R033 allelic families. The K1 and MAD20 were the predominant polymorphic allelic types at the msp-1 gene, whereas alleles belonging to 3D7/IC were more frequent at the msp-2 gene. A peculiarity of this study is that RO33 revealed a monomorphic pattern among the msp-1 allelic type. Msp-1 and msp-2 revealed considerably greater parasite diversity than glurp. A total of 27 different msp-2 genotypes were recorded of which 15 belonged to the 3D7-type and 12 to the FC27 allelic families. Alignment of peptides encoded by pfmsp1 and Pfmsp2 reveals that $\mathrm{K} 1$ polymorphism had the highest similarity in the P.fmsp1 and Pfmsp2 clade followed by MAD20 with 93\% to 100\% homology. Indicating that $P$. falciparum isolates from Cameroon present high identity with allelic sequences from other areas in Africa, suggesting that vaccine developed with $\mathrm{k} 1$ and MAD20 of Pfmsp1 allelic variant could be protective for Africa children. The MOI ranged from 2.51 for msp1 to 3.82 for msp2. The overall heterozygosity ranged from 0.55 for msp- 1 to 0.96 for msp-2 consistent with the genetic pattern observed in hyperendemic areas. Conclusion The present study reveals that isolates from South West Region of Cameroon are mainly polyclonal with high $\mathrm{MOI}$ and highly diverse in respect to both msp-1 and msp-2 despite ACTs deployment aiming at reducing malaria transmission. This study lays emphasis on the use of $\mathrm{MOI}$ and genotyping of both msp-1 and msp-2 in the evaluation of malaria control intervention in malaria endemics countries.

\section{Background}

In spite of enhanced control efforts, malaria continues to be a major public health problem in subSaharan Africa and Southeast Asia, and Plasmodium falciparum infection is prevalent in most of the endemic countries. The World Health Organization (WHO) estimated that, 219 million malaria cases occurred worldwide of which $78 \%$ was in Africa. About 407,000 fatal cases were registered, $92 \%$ in Africa and $61 \%$ of the global death in children under 5 years of age $P$. falciparum being the major cause of all deaths $[1,2]$. Malaria in Cameroon is caused by three human malaria species: $P$. falciparum, $P$. ovale and $P$. malariae. The prevalence of $P$. falciparum is about $99 \%$ while $P$. malariae and $P$. ovale share the remaining $1 \%$. The most deadly malaria is caused by $P$. falciparum. Malaria transmission in Cameroon depends on the population of Anopheles arabiensis, a member of the An. gambiae Giles complex, a principal malaria vector in Cameroon [3,4]. Malaria is a leading public health problem in Cameroon and is reported as the first cause of morbidity and mortality [5,6], accounting for $16 \%$ outpatient visits, $20 \%$ hospital admissions and $27 \%$ inpatient deaths [6-8]. Despite the current efforts to control malaria in 
Cameroon, the situation has not improved, mainly due to the increasing problems of vector resistance to insecticides [10] and resistance to almost all antimalarial drugs including ACTs [11-14]. Merozoite surface protein (MSP-1) and merozoite surface protein-2 (MSP-2) are 2 proteins causing immune responses in humans $[15,16]$ and are important candidates for development of blood stage malaria vaccines [17-19]. The msp-1 gene is located on chromosome 9 and contains 17 blocks of sequences, of which 7 are variable, flanked by conserved regions [20]. The block 2 msp-1 is particularly polymorphic and 3 distinct allelic families have been described as MAD20, K1 and Ro33 [21-25]. The msp-2 gene is located on chromosome 2 composed of five blocks of which the most polymorphic is the central block 3 [26]. The polymorphic central domain of the gene encoding MSP-2 belongs to 2 distinct families; 3D7 and Fc27 [27-29]. Allelic forms of these antigen genes have been reported from different parts of the world [18,23-32]. Differences in allelic types as well as the number of repeat sequences in $m s p-1$ and $m s p-2$ can be detected by PCR, followed by dot-blot hybridization [33]. Size polymorphism is also used not only for the msps but also for other markers including Glurp and Csp in which variations are also detected by sequencing. Genetic diversity of $P$. falciparum populations determines the intensity of malaria transmission [34-37], thus providing baseline data for any antimalarial drug efficacy trial and the possibility of implementing control strategies based on modern intervention or vaccines. Merozoite surface proteins 1 and 2 genotyping is widely used in malaria molecular epidemiology studies to assess the allelic diversity and multiplicity of infection as a proxy of transmission level in molecular monitoring of interventions [32,38]. ThePfmsp1, Pfmsp2 and glurp are commonly selected because they are located on different chromosomes, and this reduces the likelihood of linkage disequilibrium $[39,40]$. Genotyping of these genes has been effectively used to trace individual clones over time in cohort studies and to measure duration of infection $[41,42]$. Different clones of $P$. falciparum can be determined using regions of highly polymorphic genes coding for MSP-1 and MSP-2, and GLURP. These markers are equally essential in distinguishing recrudescence from reinfection of the parasite in an anti-malarial treatment trial [29,43-46], since the discriminating power of these markers is dependent on the extent of allelic diversity and on the frequency of each allele within a population $[29,47]$. Genetic diversity of $P$. falciparum has been used to implement specific strategies for control and to evaluate the impact of interventions on changes in malaria epidemiology $[10,111]$. However, in Cameroon, there are no or limited data on $\mathrm{MOI}$ and P. falciparum genetic diversity respectively, especially when $m s p-1, m s p-2$ and glurp need to be considered together as molecular markers in genotyping studies. Thus, the aim of this study was to characterize the highly polymorphic genetic markers of $P$. falciparum field isolates, including the merozoite surface protein 1 and 2 ( $m s p-1)$, the merozoite surface protein $2(m s p-2)$ and glutamate rich protein (g/urp) and to determine the allele distribution and factors influencing the $\mathrm{MOI}$ and heterozygosity as indicator of malaria parasite transmission dynamics

\section{Methods}

\section{Study site}


This study was performed in the Cameroon Development Corporation (CDC) which is an agro-industrial company based in the South West region of Cameroon specialised in the production of rubber, palm oil etc. Cameroon is distinguished by an overall climate which varies with terrain, from tropical rain forest with mean annual temperature of $24.5^{\circ} \mathrm{C}$ in the south coastal regions to $26.5^{\circ} \mathrm{C}$ in the semiarid Northern regions. Concerning the Elevation extremes, the lowest point is the Atlantic Ocean at 0 meter and the highest point is Fako (peak of Mount Cameroon) at 4,095 meters above the sea level. The CDC is a parastater company hosting rural communities in the South West region of the country which is about $30 \mathrm{~km}$ south of Buea town and $45 \mathrm{~km}$ from Douala (figure 1). The CDC company has headquarters in Limbe town headed by a Director, with a population of about 45,000 workers. The population is heterogeneous consisting primarily of peasant farmers with over $60 \%$ coming from the North West and western region of Cameroon. Limbe has 8 primary and two secondary schools. The community has good access roads, good pipe-borne water and electricity supplies. There is a good health system consisting of two reference hospitals as primary health centers in Limbe town and twenty three satellite clinics located in different towns of the south west region of Cameroon. Apart from the CDC Primary Health Centre and hospitals, there are also private clinics, mission and government health centers and hospitals. The South West region of Cameroon has a Cameroonian-type equatorial climate that favors the proliferation of mosquitoes, the vector of malaria. The climate is characterized by fairly constant temperatures and two seasons: a short dry season (November-February) and a long rainy season (March-November) with abundant precipitation $(2,000-10,000 \mathrm{~mm})$ [48]. The mean annual rainfall is $2,625 \mathrm{~mm}$, relative humidity is constantly high $(75 \%-80 \%)$, and the temperature varies from $18^{\circ} \mathrm{C}$ in August to $27^{\circ} \mathrm{C}$ in March [3]. In general, malaria transmission is intense and perennial in the South West region, with peak periods corresponding to the rainy season [48]. Three anopheles vectors including Anopheles gambiae, $A$. funestus and $A$. nili have been identified in malaria transmission in South West Region. A. gambiae the most dominant in terms of aggressiveness and activity $[3,4,22]$ accounts for up to $72.7 \%$ of transmission, Infection rates of 87 infective bites/person/year [4] and overall entomologic inoculation rate (EIR) estimated recently at 3.93 infective bites/person/night [22].In addition, houses are grouped into camps which are structured buildings provided by the company to accommodate the workers and their families.

\section{Sampling and Parasite collection}

P.falciparum isolates were collected from microscopically diagnosed $P$. falciparum positive patients aged six months to 6 years, in clinics and hospitals of CDC Cameroon. Consent to participate in this study was obtained from parents or guardians and blood sample was taken from each patient using finger prick for thick and thin blood films. 2-3 drops of blood were collected on $3 \mathrm{MM}$ Whatman filter paper. A total of 315 blood samples were collected from 23 clinics and 2 hospitals of the CDC Cameroon belonging to 2 different health districts. 


\section{Microscopy}

Blood films were stained with diluted Giemsa stain and then examined microscopically for the presence of malaria parasites; 200 fields under 1000x magnification were examined from the thick film before the slide was considered negative. For positive slides, parasitaemia (parasite density) was determined by counting only the asexual stages against 200 white blood cells (WBC) and then multiplied by 25 , assuming the average of total WBC count of individuals equal to $8000 \mathrm{cells} / \mu \mathrm{l}$ of blood. The level of parasitaemia was graded as low (< 1000 parasites/ $\mu$ l of blood), moderate (1000 - 9999 parasites/ $\mu \mathrm{l}$ of blood) and severe ( $\geq 10,000$ parasites/ $\mu$ l of blood).

\section{Molecular identification and genotyping}

Genomic DNA was extracted from blood spots collected on filter papers. Briefly, a disc of the filter paper was punched out from the blood spot using a paper puncher and placed in $1.5 \mathrm{ml}$ centrifuge tubes using clean forceps. Genomic DNA was extracted using Qiagen blood and tissue kit (QIAGEN, Germany) according to the manufacturer's instruction.

\section{Nested PCR amplification and allele detection}

DNA was eluted using $50 \mu \mathrm{L}$ AE (10 mM Tris-Cl; $0.5 \mathrm{mM}$ EDTA; pH 9.0) elution buffer (QIAGEN, DNeasy® Blood \& Tissue Kit, Cat. no. 69506 , Germany) and kept at $-20^{\circ} \mathrm{C}$ until used for PCR. Genomic DNA was amplified by Nested PCR using allelic specific Primers (Table 1) and conditions for PCR amplification were followed as previously described $[15,39,49]$ for family specific allele analysis of $m s p-1$ (block 2 ), msp-2 (block 3) and Glurp (region II). In the primary PCR, a $25 \mu \mathrm{l} \mathrm{PCR} \mathrm{mixture} \mathrm{was} \mathrm{used} \mathrm{containing} 1 \mu \mathrm{l}$ of DNA template, $0.2 \mu \mathrm{M}$ of each primer, $1 \times$ TBE buffer, $250 \mu \mathrm{M}$ of dNTPs, nuclease free water, $1 \mathrm{U}$ of Taq polymerase enzyme, $2 \mathrm{mM} \mathrm{MgCl} 2,10 \mathrm{mM} \mathrm{KCl}$, and $10 \mathrm{mM}$ Tris- $\mathrm{HCl}$, at $\mathrm{pH}$ 8.3. All reagents were from TIAGEN (Biotechnology, Inc., Beijing). Cycling conditions for the primary PCR were as follows; starting with three single steps of denaturation at $94^{\circ} \mathrm{C}$ for 5 minutes, annealing at $58^{\circ} \mathrm{C}$ for 2 minutes and extension at $72^{\circ} \mathrm{C}$ for 2 minutes. This was followed by 35 cycles of denaturation at $94^{\circ} \mathrm{C}$ for 1 minute, annealing at $58^{\circ} \mathrm{C}$ for 1 minute and extension at $72^{\circ} \mathrm{C}$ for 1 minute, then a single annealing step at $58^{\circ} \mathrm{C}$ for 2 minutes and final extension at $72^{\circ} \mathrm{C}$ for 10 minutes. $P$. falciparum genotypes were further analyzed by amplification of the two highly polymorphic regions of $m s p-1$ (Block 2 ) and $m s p-2$ (Block 3 ) using nested-PCR as previously described [49] with slight modifications for the cycling conditions of the secondary PCR. Briefly, oligonucleotide primers sets (Suppl. 1, Table1), were used for detecting the different families (K1, MAD20 and R033 in MSP-1; FC27 and IC in MSP-2). Three microliters of primary PCR products were used as the DNA templates in the secondary PCR which had similar concentrations to the primary PCR. The cycling conditions for the secondary PCR were as follows: starting with a single step of denaturation at $95^{\circ} \mathrm{C}$ for 10 minutes followed by 35 cycles of denaturation at $94^{\circ} \mathrm{C}$ for 30 seconds, annealing at $58^{\circ} \mathrm{C}$ for 30 seconds and extension at $72^{\circ} \mathrm{C}$ for 1 minute, and a final extension at $72^{\circ} \mathrm{C}$ for 10 minutes. PCR reaction mixtures were incubated in a thermal cycler. 
The secondary PCR products were separated by electrophoresis at 100 volts on $1.5 \%$ molecular grade agarose gel (Caisson, Utah, USA), stained with ethidium bromide, submerged in 0.5 X TBE (Tris-borate EDTA) buffer and visualized by UV transilluminator (BioDoc-lt UVP, Cambridge, UK) at $302 \mathrm{~nm}$ on gel documentation system. The number and size of DNA fragments were estimated based on their mobility related to a 100bp DNA ladder (Vivantis, Selangor Darul Ehsan, Malaysia). DNA fragment sizes were binned into different classes of 20 and 50 bp ranges with each bin assigned as an allele. Alleles in paired samples were considered a match for $m s p 2$ and $m s p 1$ if within 20 base pairs and for glurp if within 50 base pairs $[27,30]$

\section{Multiplicity of infection (MOl) and heterozygosity (He)}

Multiclonal infections were defined as those having more than one allele in at least one locus out of the loci genotyped. The $\mathrm{MOI}$ was determined by calculating the number of different alleles at any one locus detected in the sample[19]; single infections were those with only one allele per locus at all of the genotyped loci. Isolates with more than one genotype were considered as polyclonal infection while the presence of a single allele was considered as monoclonal infection. The mean multiplicity of infection (MOI) was determined as the quotient of the total number of $P$. falciparum genotypes detected in MSP-1 or MSP-2 by the number of samples positive for either $m s p-1$ or $m s p-2$ [50].

As a measure for genetic diversity, the expected heterozygosity (HE) which represents the probability of being infected by two parasites with different alleles at a given locus and ranging between 0 and 1 [29] was calculated by using the following formula:

$H E=[n /(n-1)][(1-\Sigma p i 2)]$, where $n$ is the number of isolates sampled and pi is the allele frequency at a given locus.

\section{Statistical analysis}

Data was analyzed using the SPSS for windows software version 17. For descriptive analysis, proportion was used to present the distribution of different allelic families while the mean was used to present the multiplicity of infection (MOI). Independent chi square test was used to compare the mean $\mathrm{MOI}$ according to gender, and parasitaemia. A p-value $\leq 0.05$ was considered indicative of a statistically significant difference.

\section{7. $m s p-1$ and $m s p-2$ sequence analysis}

Purified PCR products of isolates representing different alleles of $m s p-1$ and $m s p-2$ were sequenced in both directions with the primers of the secondary PCR using the ABI PRISM ${ }^{\circledR}$ BigDyeTM terminator Ready Reaction Cycle Sequencing Kit (Biometra Thermocycler, England) according to the manufacturer's 
instruction. The sequences were then analyzed using the DNASTAR software package (DNASTAR, Madison, $\mathrm{WI}$ ). The sequences were used to correct the estimated molecular weight and to confirm the nature and size of the amplified product. To understand the identity of Cameroonian isolates with respect to isolates of other regions, sequence data available in public domains were downloaded for allelic families of $m s p-1$ and $m s p-2$ and aligned using ClustalW method (EMBL-EBI, Hixton, and Cambridge, UK), then analysed by MEGA version 5.1 (http://mega.software.informer.com/5.1b/). We sought to identify sequence differences using BLASTN sequence homology searches. Each allelic family $m s p-1$ (including $\mathrm{K} 1, \mathrm{MAD} 20$ and R033) and $m s p-2$ (including FC27 and 3D7/IC) were analyzed separately in order to estimate the average number of nucleotide substitutions for each $m s p-2$ allele, and to examine the mode of evolution of FC27 type repeats. We assembled and aligned individual repeat units with DNAstar and BLAST searched in GenBank to analyze the distribution of the pairwise proportion of nucleotide differences among individual repeat units using isolates derived from GeneBank, namely the isolate from Gabon accession number AY372506 for FC27, the isolate HM568631 from India for 3D7/IC allelic family. As for $m s p-1$ alleles, the isolate from Brazil (accession:JX416338) for the alignment of K1-type allele, while the isolates EU032224 from central Sub Sahara Africa and AY138508 from Iran were used as reference isolate for the sequence analysis of R033 and MAD20, respectively.

\section{Results}

\section{Study profile}

Out of 315 DNA samples at baseline, 137 samples for $m s p-1$ and 307 samples for $m s p-2$ were successfully amplified by PCR, among which 107 for $m s p-1$ and 243 for $m s p-2$ were successfully sequenced.

\section{Genetic diversity and haplotype frequency}

The number of genotypes observed at each marker is shown in Table 2. Sixteen (16) different $m s p-1$ genotypes were observed, representing K1 (9 genotypes), MAD20 (6 genotypes) and RO33 (1 genotype) allelic families. The $m s p-1$ fragment sizes ranged from $153 \mathrm{bp}-335 \mathrm{bp}$, while the $m s p-2$ fragments ranged from 140 to $568 \mathrm{bp}$ both for the FC27 and IC allelic families (Table 2).

The majority (87.5\%) of these genotypes especially for the k1 (100\%) and MAD20 (97.5\%) belonging to the msp1 allelic family occurred at a frequency below $10 \%$ (Table 2). However, one genotype the MAD20 family (167-187bp) occurred above $10 \%$. The R033 family was found to be monomorphic with an amplified fragment size of $155 \mathrm{bp}$ and occurred at a frequency of $78.1 \%(107 / 137)$ (Table 3$)$ of the overall msp1 genotypes.

The $m s p-2$ diversity and genotype frequencies are shown in Figure 2a and 2b (Suppl. 2; figure 2a, 2b) while Figure $2 c$ shows the overall frequencies of $m s p-2$ genotypes. A total of 27 different $m s p-2$ genotypes (size range from 140 to $568 \mathrm{bp}$ ) were recorded of which 15 belonged to the 3D7-type and 12 to the FC27 allelic families (Table 2). The majority of these genotypes occurred at a frequency below $10 \%$ 
(figure 2c). However, 1 genotype from the 3D7/IC allelic family (420 bp-440 bp), 2 from the FC27 family (176 bp-201 bp and 201 bp-226 bp) occurred above 10\% (figure 2c). The 3D7/IC family was found to be highly polymorphic $(p=0.01)$ as compared to FC27 (Suppl. 2; figure 2a and $2 b)$.

The glurp diversity and genotype frequencies are shown in Figure 4. A total of 5 different glurp genotypes (size range from 597 to $817 \mathrm{bp}$ ) were recorded with the majority of the allelic families occurring at above $10 \%$. However, only two alleles occurred below $10 \%$ of which, $4.67 \%$ and $9.34 \%$ belonged to the $550-600$ bp and 652-702 bp allelic group.

In $m s p-1$, more than halve of the $m s p-1$ positive samples harbored all the three types of alleles of the $m s p-1$ gene. Thus the combination of RO33, MAD20 and K1 allelic families was identified with an overall frequency of $57.50 \%$ (Figure $4 a$ ). The R033 allelic family was predominant as it was identified in $78.10 \%$ $(107 / 137)$ of the samples. One third (33\%) of the blood samples positive for $m s p-1$ were identified as monoclonal infections while two-third ( $66 \%$ ) exhibited a polyclonal pattern of K1, MAD20 and R033 combination in a set of two or three alleles (Figure 4a). Among the polyclonal infections, K1/RO33, K1/MAD20 and Ro33/MAD20 constituted $6.66 \%, 1.6 \%$ and $0.83 \%$ of the $m s p-1$ positive isolates respectively. The distribution of the identified $m s p-2$ allelic families is illustrated in Figure $4 \mathrm{~b}$. Overall, $11.42 \%$ of $m s p-2$ positive isolates were identified as monoclonal infections either for 3D7/IC or FC27 allelic families against $88.56 \% \mathrm{msp}-2$ positive isolates (figure $4 \mathrm{~b}$ ) displaying a polyclonal pattern of infections. The frequency of the 3D7/IC and FC27 haplotypes combinations was found to be higher than the frequency of samples with only 3D7 or FC27 allelic families (figure 4b).

\section{Multiplicity of infection and heterozygosity}

$P$. falciparum isolates in this study had higher rates of multiple genotypes infection with an overall mean multiplicity of infection of 3.16. The mean $\mathrm{MOI}$ for $m s p$-2 loci was the highest (3.82), as compared with msp-1 (2.51) Table 3). In the children, there was no difference in mean MOI between male and female $(P=0.1)$ (Table 4). However, the influence of parasite density on genetic diversity showed that children with parasite density ranging from 2000 to 5000 had the lowest MOI (Table 5). Meanwhile those with parasite ranging from 20000 and above exhibited the highest $\mathrm{MOI}$ difference $(\mathrm{P}=0.001)$, as compared with various range of parasite densities.

The mean $\mathrm{MOI}$ was found to be higher in male patients whose parasitaemia ranged from moderate to high level, than that of male patients with low parasitaemia. The expected heterozygosity (HE) was calculated which used to estimate the fraction of all parasites that would be heterozygous for any of the two loci. Table 3 shows generally high HE values in each allelic family ranging from 0.5 to 0.65 for $m s p-1$ and from 0.94 t0 0.96 for $m s p-2$.

The influence of parasite density on genetic diversity showed that children with parasite density ranging from 2000 to 5000 had the lowest MOI (table 5) meanwhile those with parasite ranging from 20000 and above exhibited the highest $\mathrm{MOI}$ as compared with various ranges of parasite densities. 


\section{Sequence analysis of genetic polymorphism of $m s p-1$ block 2 and $m s p-2$ block3}

The $m s p-1$ block 2 and $m s p-2$ block 3 DNA fragments from PCR products with either similar or different molecular sizes in agarose gels were sequenced with the aim of further estimating the genetic diversity of the parasite population. Partial gene sequences were obtained from each end of the PCR product using the same primers for the nested PCR reactions, then DNA sequences assembled and BLAST searched in GenBank to identify identical or similar sequences. Analysis of $m s p-1$ and $m s p-2$ sequence data revealed above $80 \%$ identity of study isolates among themselves in general and above $83 \%$ with isolates from other countries with a few exceptions (Suppl. 2; Table 6). Especially, the RO33 allelic sequences of Cameroonian isolates were all very identical and had shown above $99 \%$ similarity (Suppl. 2; Table 6) with sequences reported for isolates of Kenya [51]and Indonesia [52]. In K1 family, 93 to $99 \%$ similarity was observed with K1 allelic sequences reported for isolates of Tanzania [53], Indonesia (accession no. U72950), Vietnam and Brazil [54]. Likewise, 83 to 100\% identity was observed in MAD20 family with isolates of Iran [55], Sudan [56], Vietnam [54]. Allelic families of $m s p-2$, FC27 and 3D7/IC showed 97 to $100 \%$ identity with isolates of Gambia[57],Brazil (accession no. DQ115969) Tanzania (accession no. AY378316), and Gabon (accession no. AY372518). No significant identity was found with either the Nigerian or the Brazilian isolates with respect to the 3D7/IC allelic family of this study. However 89 to 97 $\%$ identity were recorded with isolates from Gambia and Thailand [57] with the highest identity recorded with the isolates from India (97\%) [58].

\section{Discussion}

The aim of this study was to perform a molecular characterisation of highly polymorphic markers in $P$. falciparum clinical isolates. In this first study conducted after the introduction of artemisinin-combination therapies, it was observed that $P$. falciparum field isolates in Cameroon exhibited a high degree of genetic polymorphism in $P$. falciparum $m s p-1$ and $m s p-2$ markers. These genes encoding for individual functional proteins expressed on the surface of the merozoite appear to play an essential role in the invasion of the red blood cell $[59,60]$ and have captivated a lot of interest as potential vaccine candidates and as drug targets for inhibiting blood-stage replication [61-63]. Our findings revealed a high proportion of multiclonal isolates and $\mathrm{MOI}$ and a total of 16 different Pfmsp-1 and 27 different Pfmsp-2 gene types . This figure is not exhaustive since it is obvious that with nested PCR genotyping some of the subpopulations present in mixed infections would not be fully typed by all amplification steps $[42,63]$. Moreover, more amplified product was found for the msp2 gene than msp1 amplified products, this could be explained by non-synonymous substitutions introduced in template DNA that could jeopardize the proper annealing of the primer at its binding site in $m s p 1$ gene or could be explained by the fact that natural selection is more efficient when acting on $m s p-1$ than $m s p-2[59,64]$ suggesting that $m s p-1$ as compared with msp2 proteins are under strong functional constraints in a complex interaction with the host leading to an increased in host's immunological response [65]. The two markers including $m s p-1$ (16 genotypes) and $m s p-2$ (27 genotypes) revealed considerably greater parasite diversity than glurp (5 genotypes). Thus, the observed genetic polymorphism in the these two $P$. falciparum major merozoite surface proteins Pfmsp 1 and pfmsp2 could be explained by balancing selection occurring as a result of 
different mechanisms of interaction with the host [66]. This distribution of families of $m s p-1$ and $m s p-2$ and their allelic variations were similar to that reported from other countries with meso- to high endemicity of malaria $[67,68]$. Genotyping procedure recommended in antimalarial drug trials stipulates consecutive analysis of the three markers starting with $m s p 2$ or glurp, and then $m s p 1$ [111]. Based on allelic profile of each gene obtained in this study, parasitological outcome assessment could be more accurate when both markers $m s p-1$ and $m s p-2$ are included in the genotyping of recurrent parasitemias in antimalarial drug trials, consistent with other studies [42]. Our findings equally raise concern over the use of glurp genotyping in antimalarial drug trials since this marker revealed limited allelic families as compare to $m s p-1$ and $m s p-2$.

\section{Genetic diversity for $m s p-1$ and $m s p-2$ Allelic famillies}

The present study reported higher numbers of alleles (43 alleles for both MSP-1 and MSP-2) than previously reported to be circulating in the study area and in the central region of Cameroon [22,27] . A peculiarity of in this study is thatRO33 was found to be monomorphic and the most predominant allele type of msp1 compared to the polymorphic K1 and MAD20 allelic families in agreement with previous studies where R033 was found to be the most predominant allelic family for msp1 locus [39,54,67-70]. However, our finding does not corroborate other studies in which R033 was identified as the least predominant allelic variant type while MAD20 was the most predominant allelic family of the msp1 locus $[22,34]$. This discrepancy could be attributed to the difference in the degree of transmission intensity. Another peculiarity of our study is that, the R033 family of $m s p-1$ did not show any polymorphism, with only 1 variant (155 bp) detected. This result differs from that of Gabon and West Uganda, where the Ro33 family was polymorphic with three and four allelic variants, respectively $[15,71]$, but was close to that in Senegal [72] and Brazil [73], showing the monomorphic nature of R033 family of msp-1. The allelic variant $\mathrm{K} 1$ was the second highly distributed after R033. This does not corroborate previous finding in the same region of Cameroon [22]. but is consistent with most findings in areas of holoendemic, mesoendemic, and hyperendemic malaria, in which the allelic variant K1 was predominant[39].The predominance of Ro33 and K1 allelic family could be attributed to the balancing selection acting on these two allelic variants[74]. The MAD20 allelic variant was the least predominant among the Pfmsp1 allelic family in agreement with other studies conducted Africa including the Gambia, Nigeria, and Gabon [ $54,70]$. This result is does not coroborate other studies reporting the predominance of MAD20 allelic variant over K-1 and RO33 allelic variants [23, 39, 74-76. This low distribution of MAD20 allelic variant could be partly explained by a purifying selection acting on MAD20 allelic type as compared with RO33 and $\mathrm{K} 1$ allelic type. This could equally be attributed to a single nucleotide substitution in DNA template that hinders proper annealing with primers designed to amplify the MAD20 allelic type [77].. An association between the distribution of $\mathrm{k} 1$ allelic families with severe malaria has been investigated $[67,78]$ while theR033 allelic family has been frequently reported in asymptomatic malaria cases[21,34]. The predominance of Ro33 seems to be beneficial for the host since the presence of this allele type is related to reduced risk of clinical malaria[67,78].A significant correlation has been established between the genetic diversity of the $m s p-1$ gene of $P$. falciparum and parasite density. Likewise an association has 
been observed between MSP-1 allele diversity and age group on one hand, and between msp-1 allele diversity and gender among asymptomatic patients on the other hand[79].

In $m s p-2$ the allelic famillies IC/3D7 and FC27 were almost of equal frequencies consistent with other findings [55], but in contrast with previous reports showing a significant predominance of FC27 over the 3D7/IC allelic family [34]. The frequencies of individual msp2 genotypes were low with $88.9 \%$ occurring at a frequency $\leq 10 \%$. However $2(16.7 \%)$ genotypes, belonging to the FC27 and 1 (6.7\%) belonging to the 3D7/IC allelic family were found at frequencies of above $10 \%$. High genetic diversity and low allelic frequencies have been reported previously from other sites including Gabon [15], Uganda [44], Senegal [81], Burkina Faso [82]and Honduras [36].

Diversity, expressed as expected heterozygosity $(\mathrm{He})$, ranged from 0.55 for $m s p-1$ to 0.96 for $m s p-2$ suggesting that the parasite population in Cameroon, exhibits intermediate to higher heterozygosity reflecting intermediate to high transmission pattern [30] consistent with the findings in Uganda, congo and Zimbabwe showing a high heterozygosity ranges between 0.78 and 0.8 for $m s p-2[34,83]$. The correlation between the genetic variation of $P$. falciparum and malaria endemicity has been described [34$36,71]$. In areas with declining endemicity, it is reported that the number and diversity of alleles (heterozygosity) decrease with decreasing $P$. falciparum transmission [32,83]. The present study reveals that the $m s p-2$ gene is highly polymorphic as compared with $m s p 1$ gene. This observation is different in low transmission settings where high diversity has been recorded for $m s p-1$ as compared with the $m s p-2$ gene $[23,32]$. Hence, the high allelic diversity together with the low frequency of individual circulating alleles observed in the present study increase the discriminatory power of $m s p-1$ and $m s p-2$ to differentiate between recrudescence and re-infection. Thus, this study reinforce the importance for the genotyping of $P$. falciparum based on $m s p-1$ and $m s p-2$ in antimalarial drug efficacy trials, to distinguish between re-infection as recrudescence and emphasize on the importance of implementing $m s p-1$ and $m s p-2$ genotyping in effective malaria management and malaria control strategies in Cameroon and in endemic areas.

\section{Polyclonal infection expressed as the MOI values}

In this study most patients with $P$. falciparum infections were infected with multiple genetically distinct parasite variants with high level of polyclonal infections observed among $m s p-2(88.6 \%)$ and $m s p-1$ (33.8\%) positive isolates. Such a pattern of parasite structure is typical among $P$. falciparum populations in areas of high transmission, such as in sub-Saharan Africa where more than 10 variants can be routinely detected in an individual [32,62-64] and selection among these variants in the host is likely to play an important role in parasite diversity. In contrast, in areas of low transmission, such as in Asia or Latin America, patients may have infections with as few as a single variant[37,84]. No data on MOI was available in Cameroon before the introduction of ACT renders it difficult to draw a conclusive statement on the impact of ACTs introduction on MOI. Nevertheless, in this study, the polyclonal infection expressed as the $\mathrm{MOI}$ values were heterogeneous across the different loci, and the mean $\mathrm{MOI}$ was highest for $m s p-2$ 
than $m s p-1$ in accordance with previous studies in neighbouring countries with high intensity of malaria transmission including Congo and Gabon [85]. Higher MOI in Cameroon can be the results of multiple infectious mosquito bites or transmission of genetically diverse sporozoite inoculum from a single mosquito bite. Genetically distinct malaria parasites in natural populations have an extremely high rate of genetic recombination during the sexual stages resulting in multiple strains being transmitted simultaneously [86]. Effective recombination of parasites and mutation occurring in several rounds of DNA replication cycles will likely continue to maintain this genetic diversity. During genetic recombination, novel combinations of alleles can be generated offering beneficial features to the parasite, as driven by positive selection enabling spread alleles through the population. Since the evolutionary selection of malaria occurs both within individual hosts and within populations, determining the number of strain in an infection might be an important indicator of transmission intensity [87]. Effective malaria control measures (ACTs deployment, distribution of ITNs) have successfully reduced malaria transmission in many hyperendemic regions of sub-Saharan Africa. After an intervention, the malaria parasite population structure and transmission rate in these regions is expected to become similar to the low transmission rates of the regions of Southeast Asia and South America. The declining malaria transmission, as a result of scaling up interventions, has been shown to affect the genetic diversity pattern and population structure of $P$. falciparum [38,112]. Therefore the high $\mathrm{MOI}$ observed in this study is a reflect of high intensity of malaria transmission in Cameroon, despite several control strategies deployed at the health facilities and in the community such as distribution of free ACTs treatment and mosquito bed nets. This is in agreement with previous findings that observed an increase of $\mathrm{MOI}$ with an increase in malaria endemicity $[35,36]$ and a low $\mathrm{MOI}$ for $m s p-1$ and $m s p-2$ correlated with a low intensity of malaria transmission [37].

Therefore regular molecular epidemiological surveys need to be performed in order to monitor the genetic diversity of $P$. falciparum populations in different regions of Cameroon and the world, and then correlate parasite genotypes to the disease phenotypes [79,88-90]. Previous studies reported a reduced risk of clinical malaria associated with polyclonal infections [91] and high rate of severe malaria in individual harbouring mono-infections and very common genotypes [92, 93]. Our findings revealed an increase in the mean $\mathrm{MOI}$ according to parasite density but not according to the gender of patients which is consistent with previous studies showing significantly high $\mathrm{MOI}$ in patients with moderate to high transmission $[55,94]$. In the present study, most of the positive samples were from children aged 0-5 years, and this limited range of age constraint examining the correlation between the $\mathrm{MOI}$ and age. However, previous studies showed a pattern of greater $\mathrm{MOI}$ in older individuals than younger individuals reflecting more previous exposure to infection [95] while conflicting findings, indicated decreased $\mathrm{MOI}$ with age $[96,97]$. Thus, determining the $\mathrm{MOI}$ in endemic area including Cameroon is very important since it can be used to predict clinical outcome and target population with higher attention.

\section{Genotyping by gel electrophoresis and direct sequencing}

In this study, the polymorphic surface antigens $m s p 2$, glurp, and $m s p 1$ genes for 304 isolates were successfully amplified by Nested PCR and genotyped using agarose gel electrophoresis of which 127 
$m s p-1$ and $297 m s p-2$ gene fragments with single band were selected for further characterisation by direct sequencing. In this study, the lengths of the repeat units, whose number varies between the different allelic variants, was taken into account to set bin width of $20 \mathrm{bp}$ for $m s p-1$ and $50 \mathrm{bp}$ and msp2 then glurp [30]. However, variations in bin width $[44,98]$ and the different fragment sizing methods need to be standardized to facilitate the comparison of data for a particular marker between studies. Although, genotyping method using gel electrophoresis may face some confounding factors including the variability in the electrophoretic migration of a given DNA fragment, this genotyping method could be very important where alternative method are not available and is widely used for $P$. falciparum genotyping $[88,89]$ beside capillary electrophoresis $[40,69,99,100]$ recognise to have higher resolution power than gel electrophoresis in the ability to distinguish between allelic variants of amplified fragments. However, PCR artefacts are a challenge for this method and $\mathrm{MOI}$ determination is often underestimated not only with gel electrophoresis but also with capillary electrophoresis analysis especially when genotyping strategy do not considered separate nPCRs for each allelic family [42]. In contrast to previous studies, a separate nPCR followed by direct sequencing was performed in the present study enabling accurate determination of the fragments sizes for $m s p 1$ and $m s p 2$ allelic families as well as sequence motifs and nucleotide differences. The development of single-nucleotide polymorphism-based genotyping techniques and nextgeneration sequencing, might provide highly diverse haplotype markers with sufficient resolution to detect minority population in a mixed infection[101]. Thus, Next generation sequencing technologies and genome-wide characterization could be an alternative strategy to accurately analyse polyclonal infections [103] although complete haplotype characterization of multiclonal infections remains a challenge due to PCR artefacts and sequencing errors $[103,104]$. Therefore, in order to accurately study the competition and selection between variants in mixed malaria infection, new tools, more sensitive to detect minority populations and quantitative for relative parasite population sizes are required [105]. Another strategy could be the combination of sequencing method and efficient computational tool for an effective characterisation of allelic variants. A good number of software packages are being developed to analyse genome-wide SNP data of field isolates for the estimation of the presence of multiple genotypes, especially minor allele in multiclonal infections $[106,107]$

\section{Sequence analysis of genetic polymorphism of $m s p-1$ and $m s p-2$}

This study showed highly diverse nature of $P$. falciparum isolates of Cameroon in respect to length and sequence motifs. Sequencing and gene alignment confirmed the identity Pfmsp 1 and Pfmsp2 polymorphisms. Thus, when performing the gene alignment, we found high similarity between the peptides in Pfmsp 1 and pfmsp2 of Cameroon and in the other regions in Africa. However, from all peptides analyzed, the region of the alignment corresponding $\mathrm{K} 1$ polymorphism had the highest similarity among all the species in the Pfmsp clade included in this study ranging from $93 \%$ to $99 \%$ homology with previously described polymorphism in isolate from Kenya and Tanzania. The MAD20 peptide sequence polymorphism was the second most conserved with $83 \%$ to $100 \%$ homology between $P$. falciparum isolates of Cameroon and other region of Africa and other region of the world. Thus the development of a vaccine based on $\mathrm{K} 1$ and MAD20 allelic variant could likely be effective in providing immune protection against malaria in those regions in Africa, although it is not yet known to what extent the high allelic 
diversity within the K1-like and MAD20-like allelic types is of immunological significance 66]. However, previous analysis indicated more serological variation among the allelic sequences of the K1-like compared to the MAD20-like type [108,109], and more effort has been made to incorporate the repeat sequence variation of the $\mathrm{K} 1$-like alleles in recombinant antigens towards design of a multivalent vaccine $[64,77,110]$ and more than 500 different $m s p 1$ block 2 allelic sequences has been described, providing a reference for molecular epidemiological studies and potentially for design of a multi-allelic vaccine[66]. Sequencing and immunologic characterization of other allelic variants such as MAD20 for Pfmsp 1, alongside with $3 \mathrm{D} 7 / \mathrm{IC}$ for pfmsp 2 should be conducted to obtain more useful information.

\section{Conclusions}

In this first study conducted five years after the introduction of artemisinin-based combination therapies, we investigated the genetic diversity of $P$. falciparum isolates from children aged 6 months to 6 years. The present study shows that field isolates of South West Region of Cameroon were found to be mainly polyclonal with high $\mathrm{MOI}$ and highly diverse in respect to both $m s p-1$ (block 2) and $m s p-2$ (central repeat region, block 3).These markers appear to be highly polymorphic with low allelic frequencies as compared to glurp. This observation reinforced the value of $m s p-1$ and $m s p-2$ markers of $P$. falciparum for PCR correction of treatment outcomes in classifying recurrent post-treatment $P$. falciparum episodes as recrudescence or new-infections in drug clinical trials. This study lays emphasis on the use of both $m s p-1$ and $m s p-2$ genes in monitoring the trend of malaria epidemiology, and the use of $\mathrm{MOI}$ as an important indicator in the evaluation of malaria control interventions. The High MOI observed in this study is an indication that malaria transmission remains high in Cameroon despises a large distribution of ACTs and calls for intensifying control intervention. Besides, our findings reveal that population structure of $P$. falciparum isolates is identical in Cameroon as revealed by presence of common allelic composition and the high level of identity among allelic sequences from Cameroonian isolates and that of other areas in Africa and in the world and that P.falciparum population is a mixture of different strains. Therefore, vaccine developed with $\mathrm{k} 1$ and MAD20 of Pfmsp1 allelic variant could be protective for Africa children but this finding will require further genetic and immunological characterisation. It is anticipated that, clonal selection could not be the uniform across the country considering the varied climate range observed in Cameroon moving from the northern region (with sahel desert) to the south (with equatorial dense forest) corresponding to different of malaria epidemiology. Therefore, it will be relevant to carry out studies on the genetic diversity of $P$. falciparum isolates from other regions of Cameroon with varied malaria epidemiology as well as longitudinal studies involving other malaria transmission related markers such as CSP to further understand the clonal fluctuations associated with transmission intensity.

\section{Abbreviations}

ACTs: $\quad$ artenisinin-based combination therapy

CDC: $\quad$ Cameroon Development Corporation 
EDTA: $\quad$ Ethylen diamine tetraacetic acid

He: Heterozygosity

MOI: $\quad$ Multiplicity of infection

Pfmsp1: $\quad$ Plasmodium falciparum merozoite surface protein 1

Pfmsp2: $\quad$ Plasmodium falciparum merozoite surface protein 2

Glurp: $\quad$ glutamate rich protein

CSP: $\quad$ Circumsporozoite protein

PCR: $\quad$ polymerase chain reaction

TBE: $\quad$ Tris-borate EDTA

\section{Declarations}

\section{Ethics approval and consent to participate}

Parent or guardian of participants provided written informed consent before enrollment in this study in accordance with the principles of the World Health Assembly of 1975 on Ethics in Human experimentation and the Helsinki Declaration. All malaria patients received antimalaria drug free of charge. This study was approved by the Ethics Committees of the Ministry of Public Health Cameroon and by the provincial CDC authorities and retrospectively registered with controlled-trials.com in the website: https://clinicaltrials.gov/ct2/show/NCT02974348 under the registration number NCT02974348

\section{Consent for publication}

Not applicable

\section{Availability of data and material}

All data generated and/or analysed during this study are included in this published article [and its supplementary information files] and are available from the corresponding author on reasonable request. 


\section{Competing interests}

All authors declared no conflict of interest.

\section{Funding}

This study received grant support from the Chinese National Science and Technology Major Project (grant No. 2012ZX10004-220), China UK Global Health Support Programme (grant no. GHSP-CS-OP1), and International Collaboration Project from the Ministry of Science and Technology (grant No. 2010DF33970) as part of their program towards malaria control and malaria elimination. The funders had no role in study design of the trials or in the design of the analysis, data collection, decision to publish, or preparation of the manuscript.

\section{Authors' contributions}

MTN and ZXN designed and organized the study. ZXN, JHC and SMR supervised the study. MTN, PFG, XZ and JHC carried out the field and laboratory work and preliminary data analysis. MTN drafted and wrote the manuscript. PFG analysed data and wrote the manuscript. All authors read and approved the final manuscript.

\section{Acknowledgements}

Our profound gratitude to all participants, patients and CDC staff. We acknowledge the technical support of Mrs. Mbanga Christine who set up SPSS database for data entry and for statistical analysis.

\section{References}

1. WHO 2010: Guidelines for the treatment of malaria-Second Edition, World Health Organization.2010, Pp1-194. http://www.who.int/malaria/publications/atoz/9789241547925/en/index.html) .

2. WHO. World malaria report 2018. Geneva: World Health Organization; 2018.

3. Wanji S, Tanke T, Atanga SN, Ajonina C, Nicolas T, Fontenille D: Anopheles species of the Mount Cameroon region: biting habit, feeding behaviour and entomological inoculation rates. Trop Med Int Health 2003, 8:643-649.

4. Bigoga JD, Manga L, Titanji VPK, Coetzee M, Leke RGF: Malaria vectors and transmission dynamics in coastal south-western Cameroon. Malar J 2007;6:5-17.

5. NMCP (2007). National Malaria Control Program malaria report 2007. 
6. Ministry of Public Health: le point de la lutte contre le paludisme en; 2008. Rapport de progrès $\mathrm{N}^{\circ} 2$. www.minsante-gov-cm, consulted onSept.16th 2011.

7. Moyou-Somo R, Essomba P, Songue E, Tchoubou NN, Ntambo A, Ngo Hiol H, Kemajou JP, Essi M-J, Millet $\mathrm{P}$ : A public private partnership to fight against malaria along the Chad-Cameroon pipeline corridor: I.Baseline data on socio-anthropological aspects, knowledge, attitudes and practices of the population concerning malaria. BMC Public Health 2013 13:1023.

8. The Global Fund to Fight AIDs, Tuberculosis, and Malaria. (2014, January 31). Cameroon Malaria Concept Note.

9. The World Bank. (2016, April 12). International Development Association Project Appraisal Document.

10. Boussougou-Sambe ST, Eyisap WE, Tasse6 GC, Mandeng SE, Mbakop LR, Enyong P , Etang J, Fokam EB, Awono-Ambene PH. Insecticide susceptibility status of Anopheles gambiae (s.l.) in South-West Cameroon four years after long-lasting insecticidal net mass distribution. Parasites \& Vectors (2018) 11:391

11. Mbacham WF, Njuabe MT, Evehe MS, Moyou R, Skobo A. Antimalarial drug studies in Cameroon reveal deteriorating fansidar and amodiaquine cure rates. Malaria research and control in Cameroon. J. Cam. Acad. Sci. 2005, 5: 58-63.

12. Metoh Njuabe T, Tahar, R, Same-Ekobo, A, Foumane Ngane, V, Soula, G, Basco, L K Molecular Epidemiology of Malaria in Cameroon XXIX. Characterization of DHFR and Drug Resistance Markers and Efficacy of Sulfadoxine-PyrimethamineMonotherapy in Children in Niete(HEVECAM). Sciences et Médecines d'Afrique/Sciences and Medicines in Africa 2010, 2(1):146-152.

13. Dondorp AM, Nosten F, Yi P, Das D, Phyo AP, Tarning J, Lwin KM, Ariey F, Hanpithakpong W, Lee SJ, Ringwald P, Silamut K, Imwong M, Chotivanich K, Lim P, Herdman T, An SS, Yeung S, Singhasivanon P, Day NPJ, Lindegardh N, Socheat D, White NJ: Artemisinin Resistance in Plasmodium falciparum Malaria. N Engl J Med 2009, 361:455-467.

14. Dondorp, A.M., Yeung, S., White, L., Nguon, C., Day, N.P., Socheat, D. \& von Seidlein, L. (2010). Artemisinin resistance: current status and scenarios for containment. Nature Review Microbiology 8(4): 272- 280

15. Aubouy A, Migot-Nabias F, Deloron P. 2003. Polymorphism in two merozoite surface proteins of Plasmodium falciparumisolates from Gabon. Malaria Journal, 2, 12.

16. Bouyou-AkotetMK, M’Bondoukwé NP \& Mawili-Mboumba DP: Genetic polymorphismof merozoite surface protein-1 in Plasmodium

falciparum isolates from patients with mild to severe malaria in Libreville, Gabon. Parasite, 2015, 22, 12.

17. Moorthy VS, Good MF, Hill AV S. Malaria vaccine developments. Lancet 2004; 363: 150-56

18. Ferreira MU, Hartl DL: Plasmodium falciparum: worldwide sequence diversity and evolution of the malaria vaccine candidate merozoite surface protein-2 (MSP-2). Exp Parasitol 2007, 115:32-40. 
19. Patel P, Bharti PK , Bansal D, Raman RK, Mohapatra PK, Sehgal R, Mahanta J, Sultan A A, Singh N. Genetic diversity and antibody responses against

Plasmodium falciparum vaccine candidate genes from Chhattisgarh, Central India: Implication for vaccine development PLOS ONE | https://doi.org/10.1371/journal.pone.0182674 August 7, 2017

20. Woehlbier U, Epp C, Kauth CW, Lutz R, Long CA, Coulibaly B, et al. Analysis of antibodies directed against merozoite surface protein 1 of the human malaria parasite Plasmodium falciparum. Infect Immun. 2006;74:1313-22.

21. Amodu OK, Adeyemo AA, Ayoola OO, Gbadegesin RA, Orimadegun AE, Akinsola AK, Olumese PE, Omotade 00: Genetic diversity of the msp-1 locus and symptomatic malaria in south-west Nigeria. Acta Trop 2005, 95:226-232.

22. Wanji S, Kengne-Ouafo AJ, Eyong EJ, Kimbi HK, Tendongfor N, Ndamukong-Nyanga JL, NanaDjeunga HC, Bourguinat C, Sofeu-Feugaing DD, Charvet CL: Genetic diversity of Plasmodium falciparum merozoite surface protein-1 block 2 in sites of contrasting altitudes and malaria endemicities in the Mount Cameroon region. Am J Trop Med Hyg 2012, 86:764-774.

23. Kang J M, Moon S U, Kim J Y, Cho S H, Link K, et al. 2010 Genetic polymorphisms of merozoite surface protein-1 in Plasmodium falciparum field isolates from Myanmar Malaria J 2010. 9(131) 1-8

24. Mawili-Mboumba DP, Mbondoukwe N, Adande E, Bouyou-Akotet MK. Allelic Diversity of MSP1Gene in Plasmodium falciparum from Rural and Urban Areas of Gabon. Korean J Parasitol 2015; 53(4): 413-419.

25. Adel E, Tahareh D (2014) Genetic Diversity of Variable Region Block 2 in the Merozoite Surface Protein-1 (MSP1) in Plasmodium falciparumField Isolates from South-East of Iran. Malar Chemoth Cont Elimination 3:124. doi:10.4172/ 2090-2778.1000124

26. Mohammed H, Kassa M,Assefa A, Tadesse M, Kebede A. Genetic polymorphism of Merozoite Surface Protein-2 (MSP-2) in Plasmodium Tanabe K, Mackay M, Goman M, Scaife JG. Allelic dimorphism in a surface antigen gene of the malaria parasite Plasmodium falciparum. J Mol Biol.1987;195:273-87.

27. Basco LK, Tahar R, Escalante A.Molecularepidemiologyofmalariain Cameroon. XVIII. Polymorphisms of the Plasmodiumfalciparummerozoitesurfaceantigen-2geneinisolatesfromsymptomatic patients. Am J Med Hyg. 2004; 70:238-244.

28. Mohammed H, Kassa M,Assefa A, Tadesse M, Kebede A. Genetic polymorphism of Merozoite Surface Protein-2 (MSP-2) in Plasmodium falciparum isolates from Pawe District, North West Ethiopia. PLoS One. 2017; 12(5): e0177559.

29. Jamil K F, Supargiyono S, Syafruddin D, Pratama, Silvy S. Genetic diversity of merozoite surface protein-2 in Plasmodium falciparum isolates from Aceh province, Indonesia. IOP Conf. Series: Earth and Environmental Science 125 (2018) 012036 doi :10.1088/1755-1315/125/1/012036

30. Mwingira F, Nkwengulila G, Schoepflin S, Sumari D, Beck H-P, Snounou G, Felger I, Olliaro P, Mugittu K: Plasmodium falciparum msp1, msp2 and glurp allele frequency and diversity in sub-Saharan Africa. 
Malar J 2011, 10:79.

31. Mohammed H, Mindaye T, Belayneh M, Kassa M, Assefa A, Tadesse M, Woyessa, Mengesha T, Kebede A. Genetic diversity of Plasmodium falciparumisolates based on MSP-1 and MSP-2 genes from Kolla-Shele area, Arbaminch Zuria District, southwest Ethiopia. Malar J. 2015; 14:73 doi: 10.1186/s12936-015-0604-8

32. Huang B, Tuo F, Liang Y, Wu W, Wu G, Huang S, Zhong Q, Su X-Z5, Zhang H, Li M, Bacar A, Abdallah6 SKI, Mliva ASA, Wang Q, Yang Z, Zheng S, Xu Q, Song J, Deng C. Temporal changes in genetic diversity of $m s p-1, m s p-2$, and $m s p-3$ in Plasmodium falciparum isolates from Grande Comore Island after introduction of ACT. Malar J (2018) 17:83 https://doi.org/10.1186/s12936-018-2227-3

33. Smythe JA, Coppel RL, Day KP, Martin RK, Oduola AMJ, Kemp DJ, and Anders RF. Structural diversity in the Plasmodium falciparum merozoite surface antigen2. Proc.Nati.Acad.Sci.USA Vol.88,pp.17511755,March 1991 .

34. Babiker HA, Lines J, Hill WG, Walliker D. Population structure of Plasmodium falciparumin villages with different malaria endemicity in east Africa. Am J Trop Med Hyg. 1997;56:141-7.

35. Babiker HA, Ranford-Cartwright LC, Walliker D: Genetic structure and dynamics of Plasmodium falciparum infections in the Kilombero region of Tanzania. Trans R Soc Trop Med Hyg 1999, 93:1114.

36. Haddad D, Snounou G, Mattei D, Enamorad GI, Figueroa J, Stahl S, Berzins K: Limited genetic diversity of Plasmodium falciparum in field isolates from Honduras. Am J Trop Med Hyg 1999, 60:30-34.

37. Atroosh M, Al-Mekhlafi HM, Mahdy MAK, Saif-Ali R, Al-Mekhlaf A M, Surin J. Genetic diversity of Plasmodium falciparum isolates from Pahang, Malaysia based on MSP-1 and MSP-2 genes Parasites \& Vectors 2011, 4:233

38. Khaireh BA, Assefa A, Guessod HH, Basco LK, Khaireh MA, Pascual A, et al. Population genetics analysis during the elimination process of Plasmodium falciparum in Djibouti. Malar J. 2013; $12: 201$.

39. Snounou G. Genotyping of Plasmodium spp. nested PCR. Methods Mol Med. 2002;72:103-116.

40. Gupta V, Dorsey G, Hubbard AE, Rosenthal PJ, Greenhouse B. Gel versus capillary electrophoresis genotyping for categorizing treatment outcomes in two anti-malarial trials in Uganda. Malar J. 2010;9:19. doi: 10.1186/1475-2875-9-19.

41. Felger I, Maire M, Bretscher MT, Falk N, Tiaden A, Sama W, Beck H-P, Owusu-Agyei S, Smith TA. 2012. The dynamics of natural Plasmodium falciparum infections. PLoS One 7:e45542.

42. Messerli C, Hofmann NE, Beck H-P, Felger I. 2017. Critical evaluation of molecular monitoring in malaria drug efficacy trials and pitfalls of length-polymorphic markers. Antimicrob Agents Chemother 61:e01500-16.

43. Farnert A, Arez AP, Babiker HA, Beck HP, Benito A, Bjorkman A, Bruce MC, Conway DJ, Day KP, Henning L, Mercereau-Puijalon O, Ranford-Cartwright LC, Rubio JM, Snounou G, Walliker D, 
Zwetyenga J, Do Rosario VE.(2001)Genotyping of Plasmodium falciparum infections by PCR: a comparative multicentre study. Transactions of the Royal Society of Tropical Medicine and Hygiene95225-232.

44. Cattamanchi A, Kyabayinze D, Hubbard A, Rosenthal PJ, Dorsey G.(2003)Distinguishing recrudescence from reinfection in a longitudinal antimalarial drug efficacy study: comparison of results based on genotyping of msp-1, msp-2, and glurp. The American Journal of Tropical Medicine and Hygiene68133-139.

45. Happi CT, Gbotosho GO, Sowunmi A, Falade CO, Akinboye DO, Gerena L, Kyle DE, Milhous W, Wirth DF, Oduola MJ: Molecular analysis of Plasmodium falciparum recrudescent malaria infections in children treated with chloroquine in Nigeria. Am J Trop Med Hyg 2004, 70:20-26.

46. Mugittu K, Adjuik M, Snounou G, Ntoumi F, Taylor W, Mshinda H, Olliaro P, Beck HP: Molecular genotyping to distinguish between recrudescents and new infections intreatment trials of Plasmodium falciparum malaria conducted in Sub-Saharan Africa: adjustment of parasitological outcomes and assessment of genotyping effectiveness. Trop Med Int Health 2006, 9:1350-1359.

47. Beck HP, Felger I: Methods and techniques for clinical trials on antimalarial drug efficacy: genotyping to identify parasite population Amsterdam, The Netherlands, Geneva: Medicines for Malaria Venture; 2007, 45, Informal consultation organized by the Medicines for Malaria Venture and cosponsored by the World Health Organization.

48. Basco LK, Ngane VF, Ndounga M, Same-Ekobo A, Youmba J, Abodo RTO, Soula G: Molecular epidemiology of malaria in Cameroon. XXI. Baseline therapeutic efficacy of chloroquine, amodiaquine, and sulfadoxine-pyrimethamine monotherapies in children before national drug policy change. Am J Trop Med Hyg 2006, 75:388-395

49. Snounou G, Zhu X, Siripoon N, Jarra W, Thaithong S, Brown KN, Viriyakosol S: Biased distribution of msp1 and msp2 allelic variants in Plasmodium falciparum populations in Thailand. Trans $\mathrm{R}$ Soc Trop Med Hyg 1999, 93:369-374.

50. Joshi H Valecha N, Anju Verma et al. Genetic structure of Plasmodium falciparum field isolates in Eastern and North -Eastern India. 2007 Malaria Journal 6:60

51. Takala SL, Smith DL, Stine OC , Coulibaly D, Thera MA, Doumbo OK and Plowe CV. A highthroughput method for quantifying alleles and haplotypes of the malaria vaccine candidate Plasmodium falciparum merozoite surface protein-1 19 kDa. Malaria Journal20065:31

52. Eisen D, Billman-Jacobe H, Marshall VF, Fryauff D, Coppel RL.Temporal variation of the merozoite surface protein-2 gene of Plasmodium falciparum. Infect Immun. 1998 Jan;66(1):239-46.

53. Jiang G, Liu R, Daubenberger CA, Pluschke G.Sequence analysis of the MSP 1 gene of Plasmodium falciparum isolates from Hainan, China.Zhongguo Ji Sheng Chong Xue Yu Ji Sheng Chong Bing Za Zhi. 1999;17(5):294-7.

54. Ferreira MU, Ribeiro WL, Tonon AP, Kawamoto,F and Rich SM(2003). Sequence diversity and evolution of the malaria vaccine candidate merozoite surface protein-1 (MSP-1) of Plasmodium falciparum JOURNAL Gene 304, 65-75. 
55. Zakeri S, Bereczky S, Naimi P, Pedro Gil J, Djadid ND, Farnert A, Snounou G, Bjorkman A: Multiple genotypes of the merozoite surface proteins 1 and 2 in Plasmodium falciparum infections in a hypoendemic area in Iran. Trop Med Int Health 2005, 10:1060-1064.

56. Cavanagh DR, Elhassan IM, Roper $\mathrm{C}$, et al. A longitudinal study of typespecific antibody responses to Plasmodium falciparum merozoite surface protein- 1 in an area of unstable malaria in Sudan. $J$ Immunol 1998; 161: 347-59.

57. Dobaño, C., A. Khan, J. V. Robinson, R. R. Taylor, and J. S. McBride. 1997. Identical alleles of Plasmodium falciparummerozoite surface protein 2 in distant geographic areas and times. Parasitol. Int 46:137-142.

58. Sharma VP. Battling malaria iceberg incorporating strategic reforms in achieving Millennium Development Goals \& malaria elimination in India. Indian J Med Res. 2012;136:907-25.

59. Escalante AA, Lal AA, Ayala FJ. Genetic polymorphism and natural selection in the malaria parasite Plasmodium falciparum. Genetics. 1998; 149:189-202. [PubMed: 9584096]

60. Escalante AA, Cornejo OE, Rojas A, Udhayakumar V, Lal AA. Assessing the effect of natural selection in malaria parasites. Trends Parasitol. 2004; 20:388-395. [PubMed: 15246323]

61. Tetteh KK, Stewart LB, Ochola LI, Amambua-Ngwa A, Thomas AW, Marsh K, Weedall GD, Conway DJ. Prospective identification of malaria parasite genes under balancing selection. PLoS One. 2009; 4:e5568. [PubMed: 19440377]

62. Beeson JG, Drew DR, Boyle MJ, Feng G, Fowkes FJ, Richards JS. Merozoite surface proteins in red blood cell invasion, immunity and vaccines against malaria. FEMS Microbiol Rev. 2016;40:343-72. doi: 10.1093/femsre/fuw001 [PMC free article] [PubMed] [Google Scholar]

63. Wilson DW, Goodman CD, Sleebs BE, et al. Macrolides rapidly inhibit red blood cell invasion by the human malaria parasite, Plasmodium falciparum. BMC Biol. 2015;13:52.

64. Tetteh KK, Cavanagh DR, Corran P, Musonda R, McBride JS, Conway DJ. Extensive antigenic polymorphism within the repeat sequence of the Plasmodium falciparum merozoite surface protein 1 block 2 is incorporated in a minimal polyvalent immunogen. Infect Immun. 2005;73:5928-35.

65. Schneider KA, Escalante AA. Fitness components and natural selection: why are there different patterns on the emergence of drug resistance in Plasmodium falciparum and Plasmodium vivax? Malar J. 2013; 11:12-15.

66. Aspeling-Jones $\mathrm{H}$ and Conway DJ. An expanded global inventory of allelic variation in the most extremely polymorphic region of Plasmodium falciparum merozoite surface protein 1 provided by short read sequence data Malar J (2018) 17:345

67. Kun FJJ, Schmidt-Ott RJ, Lehman LG, Lell B, Luckner D, Greve B, Matousek P, Kremsner PG: Merozoite surface antigen 1 and 2 genotypes and rosetting of Plasmodium falciparum in severe and mild malaria in Lambarene, Gabon. Trans R Soc Trop Med Hyg 1998, 92:110-114.

68. Bharti PK, Shukla MM, Sharma YD, Singh N. Genetic diversity in the block 2 region of the merozoite surface protein-1 of Plasmodium falciparum in central India. Malaria Journal 2012 11:78. 
69. Schoepflin S, Valsangiacomo F, Lin E, Kiniboro B, Mueller I, Felger I: Comparison of Plasmodium falciparum allelic frequency distribution in different endemic settings by high-resolution genotyping. Malar J 2009, 8:250.

70. Ferreira MU, Kaneko O, Masatsugu K, Qing L, Kawamoto F, Tanabe K. Allelic diversity at the merozoite surface protein-1 (MSP-1) locus in natural Plasmodium falciparum populations: a brief overview. Mem Inst Oswaldo Cruz. 1998;93:631-638

71. Peyerl-Hoffmann G, Jelinek T, Kilian A, Kabagambe G, Metzger WG,von Sonnenburg F: Genetic diversity of Plasmodium falciparum and its relationship to parasite density in an area with different malaria endenicities in West Uganda Trop Med Int Health 2001, 6:607-613.

72. Zwetyenga J, Rogier C (1998) No influence of age on infection complexity allelic distribution in Plasmodium falciparum infection in Ndiop, a Sengales village with seasonal, mesoendemic malaria. Am J Trop Med Hyg 59: 726-735.

73. Sallenave-Sales S, Daubersies P, Mercereau-Puijalono O, rahimalala L, Contamin H; Druilhe P, DanielRibeiro CT, Ferreira-da-Cruz MF (2000) Plasmodium falciparum: A comparative analysis of the genetic diversity in malaria-mesoendemic area of Brazil and Madagascar. Parasitol Res 86: 692-698. \#

74. Irawati N: Genetic polymorphism of merozoite surface protein-1 (MSP-1) block 2 allelic types in Plasmodium falciparum field isolates from mountain and coastal area in West Sumatera, Indonesia. Med J Indones 2011, 20:11-14.

75. Montoya L, Maestre A, Cgroupona J, Lopes D, Do Rosario V, Blair S: Plasmodium falciparum: diversity studies of isolates from two Colombian regions with different endemicity. Exp Parasitol 2003, 104:14-19.

76. Yuan L, Zhao H, Wu L, Li X, Parker D, Xu S, et al. Plasmodium falciparum populations from northeastern Myanmar display high levels of genetic diversity at multiple antigenic loci. Acta Trop 2014;125(1):53-9.

77. Tetteh KK, Conway DJ. A polyvalent hybrid protein elicits antibodies against the diverse allelic types of block 2 in Plasmodium falciparum merozoite surface protein 1. Vaccine. 2011;29:7811-7.

78. Ntoumi F, Mercereau-Puijalon O, Luty A, Georges A, Millet P: High prevalence of the third form of merozoite surface protein-1 in Plasmodium falciparum in asymptomatic children in Gabon. Trans $\mathrm{R}$ Soc Trop Med Hyg 1996, 90:701-702.

79. Chaorattanakawee S, Nuchnoi P, Hananantachai H, Tumkosit U, Saunders D, Naka I, et al. (2018) Correction: Sequence variation in Plasmodium falciparummerozoite surface protein-2 is associated with virulence causing severe and cerebral malaria. PLoS ONE 13(4): e0196694.

80. Babiker HA, Walliker D (1997b) Current views on the population structure of Plasmodium faciparum: implication for control. Parasitol Today 13: 262-267. 
81. Henry M, Diallo I, Bordesj , Ka S, Pradines B, Diatta B, M'baye Ps, Sane M, Thiam M, Gueye Mp, Wade B, Touze Je, Debonne Jm, Rogier C, Fusai T: Urban malaria in Dakar, Senegal: chemosusceptibility and genetic diversity of Plasmodium Falciparum isolates. Am J Trop Med Hyg 2006,

82. Soulama I, Nébié I, Ouédraogo A, Gansane A, Diarra A, Tiono AB, Bougouma EC, Konaté AT, Kabré GB, Taylor WRJ, Sirima S: Plasmodium falciparumgenotypes diversity in symptomatic malaria of children living in an urban and a rural setting in Burkina Faso. Malar J 2009, 8:135.

83. Anderson TJ HB, Williams JT, Estrada-Franco JG, Richardson L, Mollinedo R, Bockarie M, Mokili J, Mharakurwa S, French N, Whitworth J, Velez ID, Brockman AH, Nosten F, Ferreira MU, Day KP: Microsatellites reveal a spectrum of population structure in the malaria parasite Plasmodium falciparum. Mol Biol Evol 2000, 17:1467-1482.

84. Juliano JJ, et al. (2009) Misclassification of drug failure in Plasmodium falciparum clinical trials in southeast Asia. J Infect Dis 200:624-628.

85. Ibara-Okabande, R., Koukouikila-Koussounda, F., Ndounga, M. et al. Reduction of multiplicity of infections but no change in msp2 genetic diversity in P. falciparum isolates from Congolese children after introduction of artemisincombination therapies. Malaria Journal 2012 11(Suppl 1):P70. (https://doi.org/10.1186/1475-2875-11-S1-P70.

86. Talisuna AO, Okello PE, Erhart A, Coosemans M, D’Alessandro U (2007) Intensity of malaria transmission and the spread of Plasmodium falciparum resistant malaria: A review of epidemiologic field evidence. Am J Trop Med Hyg 77(6 suppl)170-180. 87. Jiang H, Li N, Gopalan V, Zilversmit MM, Vgroupa S, Nagarajan V, Li J, Mu J, Hayton K, Henschen B, Yi M, Stephens R, McVean G, Awadalla P, Wellems TE, Su X-Z: High recombination rates and hotspots in a Plasmodium falciparum genetic cross. GenomeBiology 2011, 12: R33.

87. Hamid MMA, Elamin AF, Albsheer MMA, Abdalla AAA, Mahgoub NS, Mustafa SO, Muneer MS and Amin M. Parasites \& Vectors (2016) 9:362 DOI 10.1186/s13071-016-1641-z

88. Somé AF, Bazié T, Zongo I, Yerbanga RS, Nikiéma F, Neya C, Taho LK and Ouédraogo J-B.

Plasmodium falciparum msp1 and msp2 genetic diversity and allele frequencies in parasites isolated from symptomatic malaria patients in Bobo-Dioulasso, Burkina Faso. Parasites \& Vectors (2018) $11: 323$

89. Kiwuwa MS, Ribacke U, Moll K, Byarugaba J, Lundblom K, Färnert A, Fred K, Wahlgren M. Genetic diversity of Plasmodium falciparum infections in mild and severe malaria of children from Kampala, Uganda. Parasitol Res. 2013 Apr;112(4):1691-700. doi: 10.1007/s00436-013-3325-3.

91. Bereczky S, Liljander A, Rooth I, Faraja L, Granath F, Montgomery SM, et al. Multiclonal asymptomatic Plasmodium falciparum infections predict a reduced risk of malaria disease in a Tanzanian population. Microbes Infect. 2007;9:103-10.

92. Amodu OK, Oyedeji SI, Ntoumi F, Orimadegun AE, Gbadegesin RA, Olumese PE, et al. Complexity of the msp2 locus and the severity of childhood malaria, in south-western Nigeria. Ann Trop Med Parasitol. 2008;102:95-102. 
93. Durand R, Ariey F, Cojean S, Fontanet A, Ranaivo L, Ranarivelo LA, et al. Analysis of circulating populations of Plasmodium falciparum in mild and severe malaria in two diferent epidemiological patterns in Madagascar. Trop Med Int Health. 2008;13:1392-9.

94. Vafa M, Troye-Blomberg M, Anchang J, Garcia A, Migot-Nabias F: Multiplicity of Plasmodium falciparum infection in asymptomatic children in Senegal: relation to transmission, age and erythrocyte variants. Malar J 2008, 7:17.

95. Takala SL, Coulibaly D, Thera MA, Dicko A, et al. Dynamics of Polymorphism in a Malaria Vaccine Antigen at a Vaccine-Testing Site in Mali 2007, PLoS Med. 2007 Mar; 4(3): e93.

96. Mayor A, Saute F, Aponte JJ, Almeda J, Gómez-Olivé FX, Dgedge M, Alonso PL: Plasmodium falciparum multiple infections in Mozambique, its relation to other malariological indices and to prospective risk of malaria morbidity. Trop Med Int Health 2003, 8:3-11. 33.

97. Owusu-Agyei S, Smith T, Beck HP, Amenga-Etego L, Felger I: Molecular epidemiology of Plasmodium falciparum infections among asymptomatic inhabitants of a holoendemic malarious area in northern Ghana. Trop Med Int Health 2002, 7:421-428.

98. Zhong D, Afrane Y, Githeko A, Yang Z, Cui L, Menge DM, Temu EA, Yan G. Plasmodium falciparum genetic diversity in Western Kenya Highlands. Am J Trop Med Hyg. 2007;77:10431050.81.

99. Falk N, Maire N, Sama W, Owusu-Agyei S, Smith T, Beck HP, Felger I. Comparison of PCR-RFLP and Genescan-based genotyping for analyzing infection dynamics of Plasmodium falciparum. Am J Trop Med Hyg. 2006;74:944-950.

100. Liljander A, Wiklund L, Falk N, Kweku M, Mårtensson A, Felger I, Färnert A. Optimization and validation of multi-coloured capillary electrophoresis for genotyping of Plasmodium falciparum merozoite surface proteins (msp1 and 2) Malar J. 2009;8:78. doi: 10.1186/1475-2875-878.

101. Daniels R, Volkman SK, Milner DA, Mahesh N, Neafsey DE, et al. 2015. Genetic diversity and protective efficacy of the RTS,S/AS01 malaria vaccine. N Engl J Med 373:2025-2037. https://doi.org/10.1056/NEJMoa1505819.

102. Zhong D , Koepfi C, Cui L and Yan G Molecular approaches to determine the multiplicity of Plasmodium infections. Malar J (2018) 17:172 https://doi.org/10.1186/s12936-018-2322-5

103. Thompson, J. R., L. A. Marcelino, and M. F. Polz. 2002. Heteroduplexes in mixed-template amplifications: formation, consequence and elimination by 'reconditioning PCR'. Nucleic Acids Res. 30:2083-2088.

104. Acinas SG , Sarma-Rupavtarm R, Klepac-Ceraj V, and Polz MF. PCR-Induced Sequence Artifacts and Bias: Insights from Comparison of Two 16S rRNA Clone Libraries Constructed from the Same Sample. Appl Environ Microbiol. 2005 Dec; 71(12): 8966-8969. 
105. Hastings IM, Nsanzabana C, Smith TA (2010) A comparison of methods to detect and quantify the markers of antimalarial drug resistance. Am J Trop Med Hyg 83:489-495.

106. Assefa SA, Preston MD, Campino S, Ocholla H, Sutherland CJ, Clark TG. estMOI: estimating multiplicity of infection using parasite deep sequencing data. Bioinformatics. 2014;30:1292-4.

107. Zhu SJ, Almagro-Garcia J, McVean G. Deconvolution of multiple infections in Plasmodium falciparumfrom high throughput sequencing data. Bioinformatics. 2018;34:9-15.

108. Noranate N, Prugnolle F, Jouin H, Tall A, Marrama L, Sokhna C, et al. Population diversity and antibody selective pressure to Plasmodium falciparum MSP1 block2 locus in an African malariaendemic setting. BMC Microbiol. 2009;9:219.

109. Polley SD, Tetteh KK, Cavanagh DR, Pearce RJ, Lloyd JM, Bojang KA, et al. Repeat sequences in block 2 of Plasmodium falciparum merozoite surface Aspeling-Jones and Conway Malar J (2018) 17:345 Page 12 of 13 protein 1 are targets of antibodies associated with protection from malaria. Infect Immun. 2003;71:1833-42.

110. Cowan GJ, Creasey AM, Dhanasarnsombut K, Thomas AW, Remarque EJ, Cavanagh DR. A malaria vaccine based on the polymorphic block 2 region of MSP-1 that elicits a broad serotype-spanning immune response. PLoS ONE. 2011;6:e26616.

111. World Health Organization. 2008. Methods and techniques for clinical trials on antimalarial drug efficacy: genotyping to identify parasite populations: informal consultation organized by the Medicines for Malaria Venture and cosponsored by the World Health Organization, 29-31.

112. Escalante AA, Ferreira MU, Vinetz JM, Volkman SK, Cui L, Gamboa D, et al. Malaria Molecular Epidemiology: Lessons from the International Centers of Excellence for Malaria Research Network. Am J Trop Med Hyg. 2015; 93(3 Suppl):79-86.

\section{Tables}

Table1. Sequence of primers of $m s p 1$ and $m s p 2$ genesof $P$. falciparum from Cameroon 


\begin{tabular}{|c|c|c|}
\hline \multirow[t]{2}{*}{ Msp-1 (Block2) } & Primary PCR & $\begin{array}{l}\text { CHM1-OF: 5' CTAGAAGCTTTAGAAGATGCAGTATTG-3' } \\
\text { CHM1-OR: 5' CTTAAATAGTATTCTAATTCAAGTGGATCA-3' }\end{array}$ \\
\hline & Secondary PCR & $\begin{array}{l}\text { CHM1-KF: 5' AAATGAAGAAGAAATTACTACAAAAG GTGC-3' } \\
\text { CHM1-KR: 5' GCTTGCATCAGCTGGAGGGCTTGCACCAGA-3' } \\
\text { CHM1-MF: 5' AAATGAAGGAACAAGTGGAACAGCTGTTAC-3' } \\
\text { CHM1-MR: 5' ATCTGAAGGATTTGTACGTCTTGAATTACC-3' } \\
\text { CHM1-RF:5'TAAAGGATGGAGCAAATACTCAAGTTGTTG-3' } \\
\text { CHM1-RR: 5' CATTTGAAGGATTTGCAGCACCTGGAGATC-3' }\end{array}$ \\
\hline \multirow[t]{2}{*}{ Msp-2 (block3) } & Primary PCR & $\begin{array}{l}\text { M2-OF: 5’ ATGAAGGTAATTAAAACATTGTCTATTATA-3' } \\
\text { M2-OR: 5' CTTTGTTACCATCGGTACATTCTT'3' }\end{array}$ \\
\hline & Secondary PCR & $\begin{array}{l}\text { M2-FCF: 5' ATATTAAGAGTGTAGGTGCARATGCTCCA-3' } \\
\text { M2-FCR: 5' TTTTATTTGGTGCATTGCCAGAACTTGAAC-3' } \\
\text { M2-ICF: 5'AGAAGTATGGCAGAAAGTAAKCCTYCTACT-3' } \\
\text { M2-ICR: 5' GATTGTAATTCGGGGGATTCAGTTTGTTCG-3' }\end{array}$ \\
\hline \multirow[t]{2}{*}{ Glurp(RegionII) } & Primary PCR & $\begin{array}{l}\text { CHG-OF: 5' -TGAATTTGAAGATGTTCACACTGAAC-3' } \\
\text { CHG-OR: 5' -GTG GAATTGCTTTTTCTTCAACACTAA-3' }\end{array}$ \\
\hline & Secondary PCR & $\begin{array}{l}\text { CHG-NF: 5'-TGAATTTGA AGA TGT TCA CAC TGA AC-3' } \\
\text { CHG-OR: 5'-GTG GAATTGCTT TTTCTTCAACAC TAA-3' }\end{array}$ \\
\hline
\end{tabular}

Table 2. Base pair range and number of detected genotypes of the respective $m s p-1$ and $m s p-2$ gene families in $P$. falciparum isolates from 315 malaria patients in Cameroon

\begin{tabular}{|c|c|c|c|c|c|}
\hline \multirow[t]{2}{*}{ Marker } & \multicolumn{3}{|c|}{$m s p-1$} & \multicolumn{2}{|c|}{$m s p-2$} \\
\hline & K1 & MAD20 & R033 & FC27 & $3 \mathrm{D} 7 / \mathrm{IC}$ \\
\hline Number of different genotypes per allele & 9 & 6 & 1 & 12 & 15 \\
\hline Allele range (bp) & 153-335bp & 175-205bp & 155bp & $\begin{array}{c}140- \\
387 \mathrm{bp}\end{array}$ & $\begin{array}{l}200- \\
568 \mathrm{bp}\end{array}$ \\
\hline $\begin{array}{ll}\text { Total per locus } \\
\end{array}$ & & 16 & & & 27 \\
\hline $\begin{array}{l}\text { Genotypes frequency for allele type } \\
\text { occurring at a frequency }<10 \%\end{array}$ & $\begin{array}{l}9(100 \%) \\
(0 \%)\end{array}$ & $5(97.5 \%)$ & 0 & $\begin{array}{l}10 \\
(83.3 \%) \\
(95.3 \%)\end{array}$ & 1 \\
\hline Total per allele & & $3(87.5 \%)$ & & $24(8$ & $\%)$ \\
\hline $\begin{array}{l}\text { Genotypes frequency for allele type } \\
\text { occurring at a frequency }>10 \%\end{array}$ & $\begin{array}{l}0(0 \%) \\
1(100 \%)\end{array}$ & $1(16.7 \%)$ & & $\begin{array}{c}2 \\
(16.7 \%) \\
1(6.7 \%)\end{array}$ & \\
\hline
\end{tabular}

Table 3. Heterozygosity, and multiplicity of infection (MOI) per msp1 and msp2 allelic families in P. falciparum isolates from 315 malaria in Cameroon.

\begin{tabular}{lcccc}
\hline & Frequency & No. fragments & He & MOI \\
& & & & \\
\hline K1 (\%) & $80(58.39 \%)$ & 197 & 0.65 & 2.46 \\
MAD20 (\%) & $40(29.19 \%)$ & 40 & 0.50 & 1.00 \\
R033 (\%) & $107(78.10 \%)$ & 107 & 0.50 & 1.00 \\
Total/ msp1 & 137 & 344 & 0.55 & 2.51 \\
3D7(IC) & $295(96.1 \%)$ & 621 & 0.99 & 2.10 \\
FC 27 & $298(97.1 \%)$ & 552 & 0.94 & 1.88 \\
Total/ msp2 & 307 & 1183 & 0.96 & 3.82 \\
\hline
\end{tabular}


Table 4. Distribution of MOI by gender among children with falciparum malaria

\begin{tabular}{lccccc}
\hline & PCR+ & No. 3D7/IC fragments & No. FC27 fragment & No. FC27 + 3D7 fragment & MOI \\
\cline { 2 - 6 } Female & 157 & 43 & 21 & 175 & 1.52 \\
Male & 150 & 76 & 22 & 202 & 2 \\
Total & 307 & 119 & 43 & 377 & \\
\hline
\end{tabular}

Table 5: Distribution of msp2 allele by parasite density among children with falciparum malaria

\begin{tabular}{|c|c|c|c|c|c|c|}
\hline & PCR+ & $\begin{array}{l}\text { No. 3D7/IC } \\
\text { fragments }\end{array}$ & $\begin{array}{l}\text { No. FC27 } \\
\text { fragment }\end{array}$ & $\begin{array}{c}\text { No. FC27 + 3D7/IC } \\
\text { fragment }\end{array}$ & $\begin{array}{c}\text { Total } \\
\text { fragments }\end{array}$ & MOI \\
\hline $2000-5000$ & 123 & 54 & 39 & 95 & 188 & 1.53 \\
\hline $\begin{array}{l}5001- \\
10000\end{array}$ & 36 & 6 & 4 & 50 & 60 & 1.67 \\
\hline $\begin{array}{l}10001- \\
15000\end{array}$ & 43 & 31 & 24 & 63 & 118 & 2.7 \\
\hline $\begin{array}{l}15001- \\
20000\end{array}$ & 36 & 24 & 27 & 35 & 86 & 2.8 \\
\hline \multirow{2}{*}{$\begin{array}{l}\text { 20001- } \\
\text { Above }\end{array}$} & 69 & 64 & 51 & 115 & 230 & 3.3 \\
\hline & 307 & 203 & 162 & 358 & 723 & 2.6 \\
\hline
\end{tabular}

Figures 


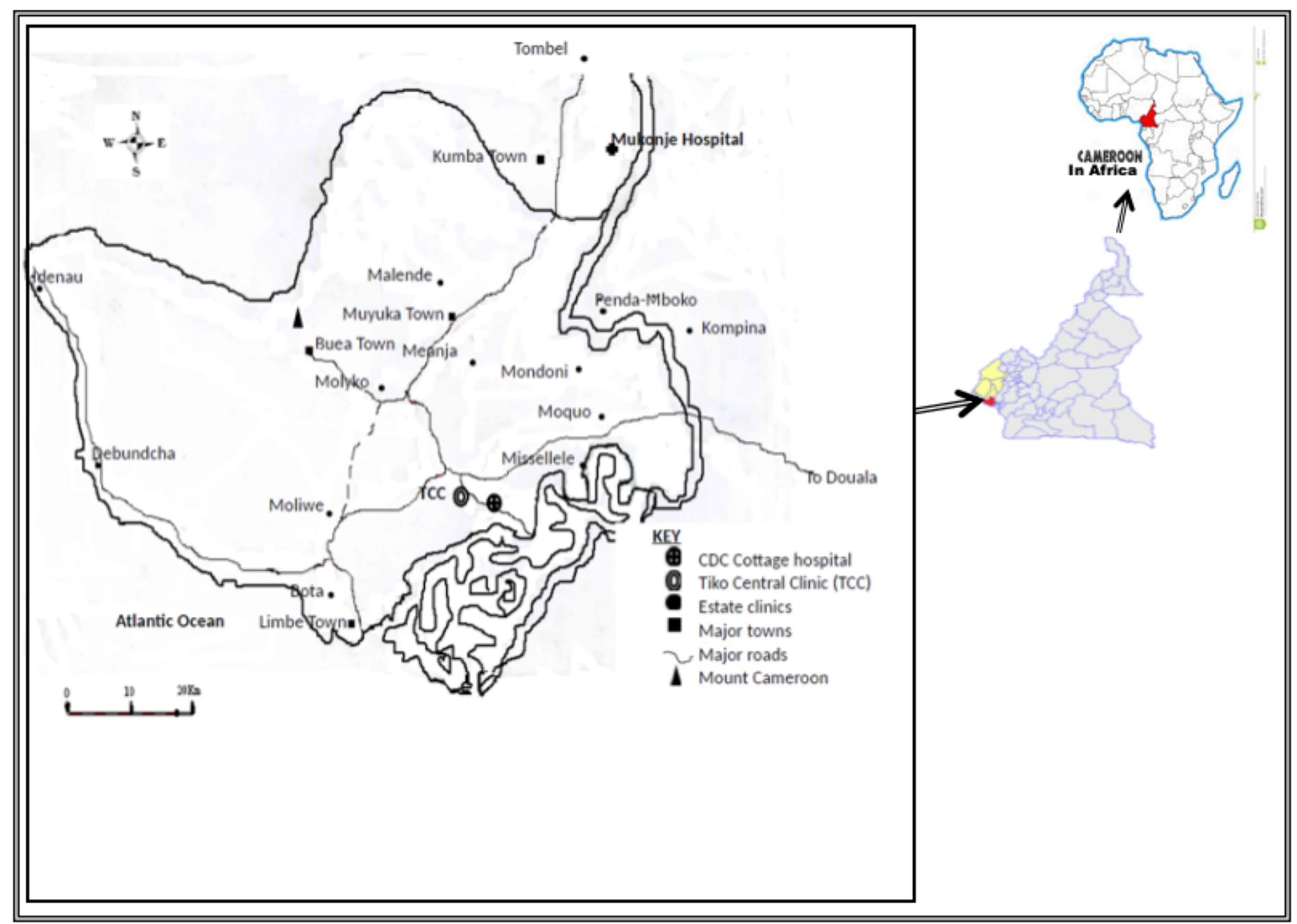

Figure 1

Map of major health facilities of the Cameroon Development Corporation (CDC), South West Region of Cameroon and Geographic map of Cameroon, Source; https://www.worldatlas.com/webimage/countrys/africa/cm.htm 


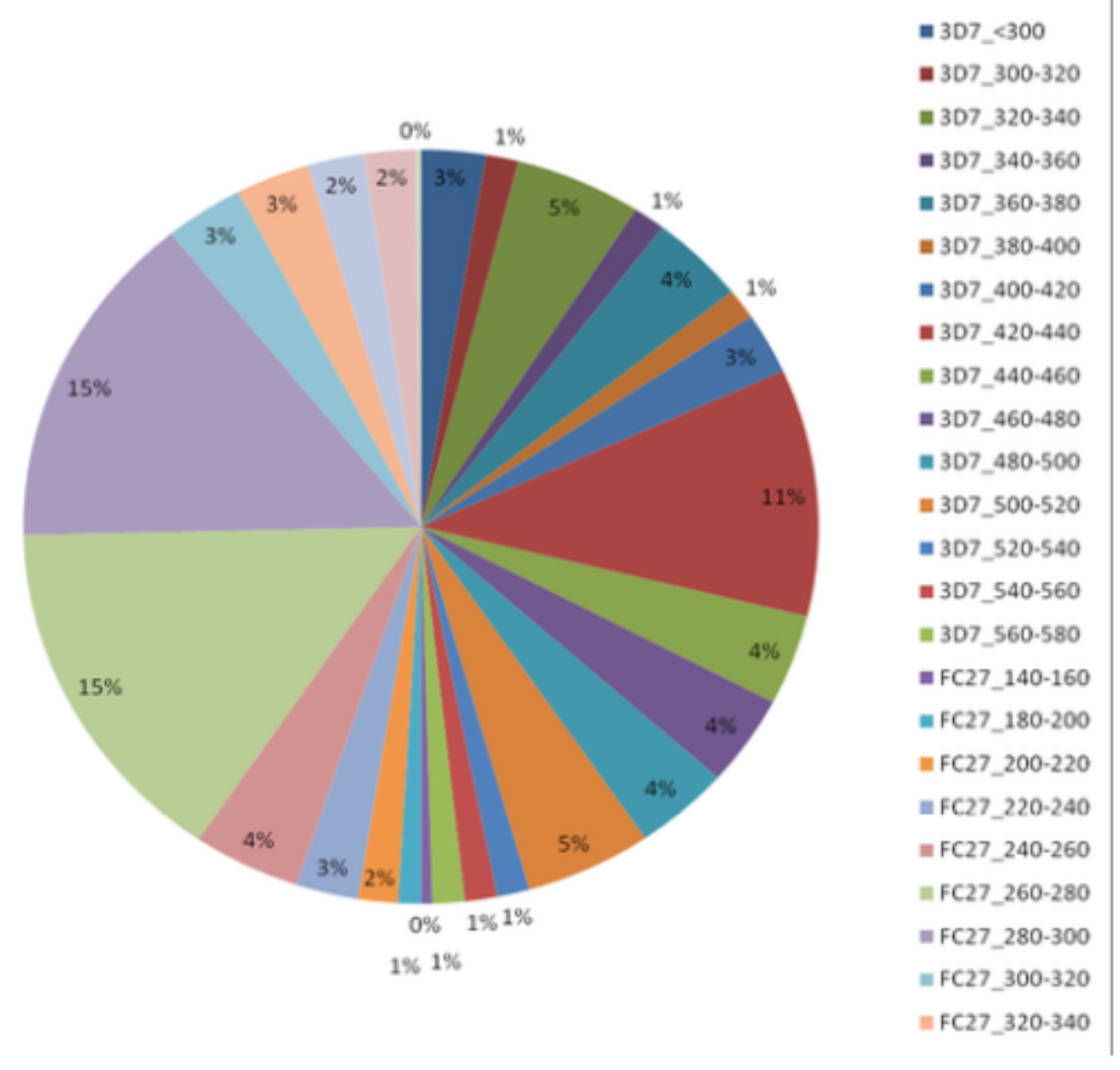

Figure 2

2a. The frequencies for 3D7/IC allelic family of msp-2 genotypes (Suppl. 2; figure 2a, 2b,2c) $2 b$. The frequencies for FC27 allelic family of msp-2 genotypes (Suppl. 2; figure 2a, 2b, 2c) 2c. Relative allele frequency in the sequenced fragments and adjusted to the overall population of msp2 (Suppl. 2; figure $2 a, 2 b, 2 c)$ 


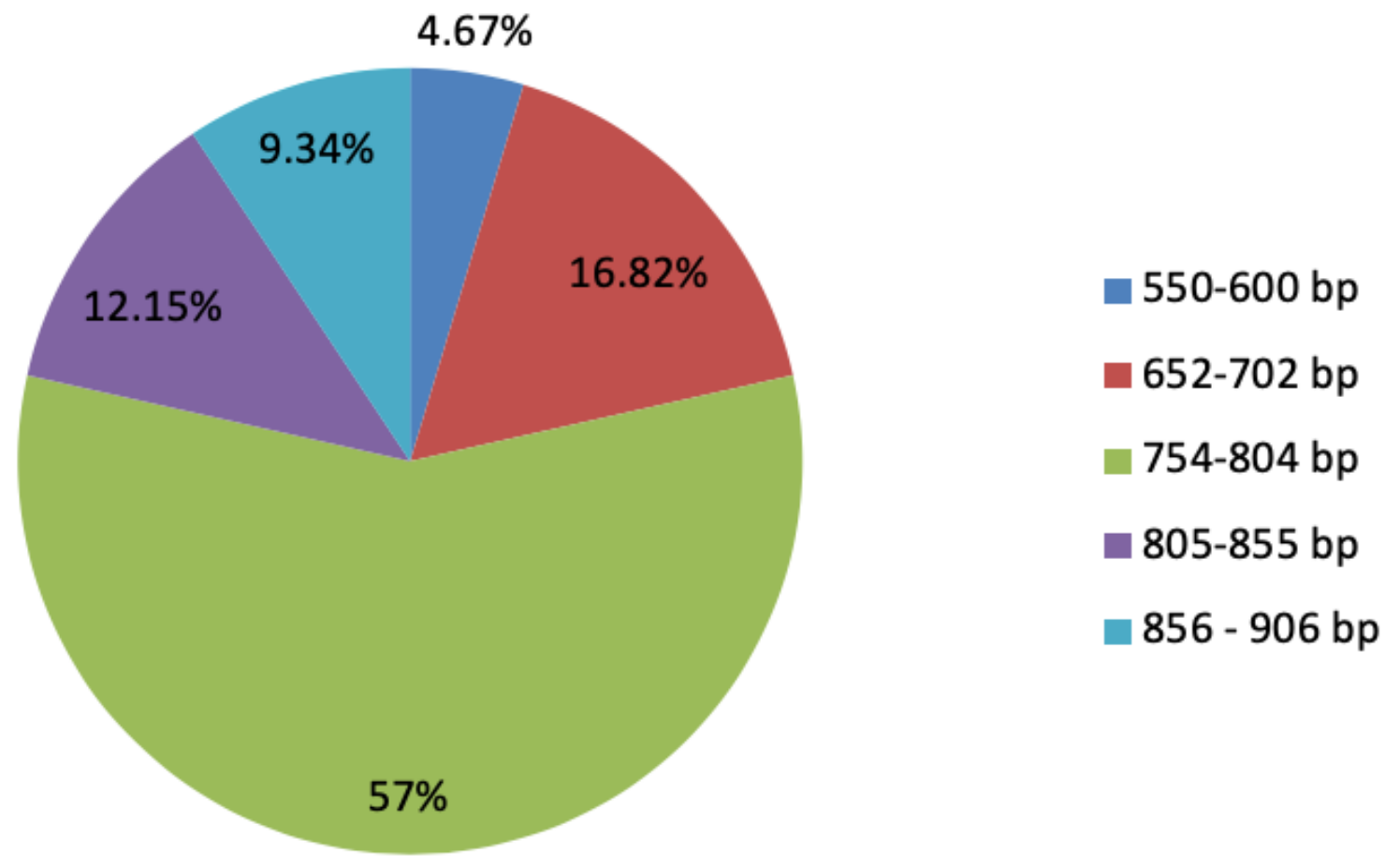

Figure 3

Allele frequency of P. falciparum glurp

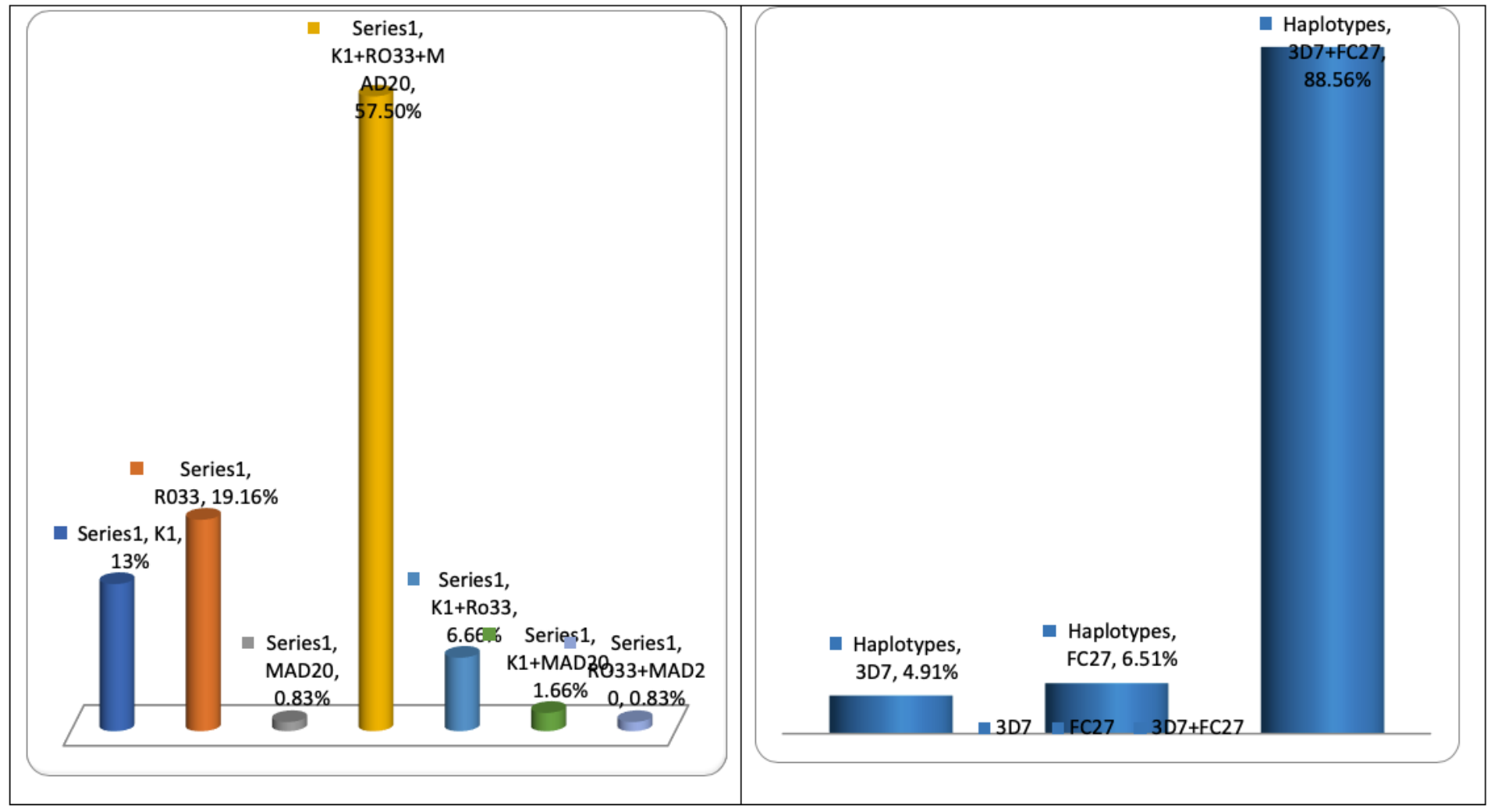


Figure 4

4a. Distribution of msp-1 haplotypes. 4b. Distribution of haplotypes for msp2 allelic family

\section{Supplementary Files}

This is a list of supplementary files associated with this preprint. Click to download.

- supplement1.docx

- supplement2.docx 